\title{
GMR
}

\section{Clinical significance of fascin-1 and laminin-5 in non-small cell lung cancer}

\author{
L. Yang ${ }^{1}$, Y. Teng ${ }^{2}$, T.-P. Han ${ }^{1}$, F.-G. Li ${ }^{1}$, W.-T. Yue ${ }^{2}$ and Z.-T. Wang ${ }^{1}$ \\ ${ }^{1}$ Department of Thoracic Surgery, Beijing Chest Hospital, \\ Capital Medical University, Beijing, China \\ ${ }^{2}$ Department of Cellular and Molecular Biology, \\ Beijing Chest Hospital, Capital Medical University, Beijing, China \\ Corresponding author: Z.-T. Wang \\ E-mail:wztdoctor@163.com
}

Genet. Mol. Res. 16 (2): gmr16029617

Received January 13, 2017

Accepted May 8, 2017

Published June 20, 2017

DOI http://dx.doi.org/10.4238/gmr16029617

Copyright $(C 2017$ The Authors. This is an open-access article distributed under the terms of the Creative Commons Attribution ShareAlike (CC BY-SA) 4.0 License.

\begin{abstract}
Lung cancer is the leading cause of cancer death in men and the second leading cause of cancer death in women worldwide. Fascin-1 and laminin-5 were associated with the invasiveness and prognoses of several cancers. The expression and the serum levels of fascin-1 and laminin-5 in patients with nonsmall cell lung cancer (NSCLC) were analyzed in this study. The expression of fascin- 1 and laminin-5 were examined in 378 patients and their serum level was measured in 154 patients. The health of all patients was followed post-surgery. The expression of fascin-1 $(\mathrm{P}=$ $0.000)$ and lanminin-5 $(\mathrm{P}=0.001)$ and the serum levels of fascin-1 $(\mathrm{P}=0.015)$ and laminin-5 $(\mathrm{P}=0.046)$ were related to the relapse of patients with NSCLC. Both serum levels and expression of fascin-1 and laminin-5 can be used to effectively evaluate the prognoses of patients with NSCLC.
\end{abstract}

Key words: NSCLC; Fascin-1; Laminin-5

Genetics and Molecular Research 16 (2): gmr16029617 


\section{INTRODUCTION}

Lung cancer was rare before the twentieth century (Page et al., 2000), but now it is the leading cause of death due to cancer in both men and women (Fitzmaurice et al., 2015). It is estimated that 1.8 million new lung cancer cases and 1.6 million lung cancer deaths (accounting for $19 \%$ of all cancer deaths) occurred in 2012 worldwide (Ferlay et al., 2013; Siegel et al., 2014; Torre et al., 2016). Non-small cell lung cancer (NSCLC) and small cell lung cancer (SCLC) are main subtypes of lung cancer, and NSCLC accounts for approximately $80 \%$ of all lung cancer cases (Page et al., 2000). The most effective treatment of early stage NSCLC is surgery; however, most patients suffer from recurrence (Wu et al., 2015). Poor prognosis has been attributed to tumor invasion, metastasis, and recurrence. Therefore, determination of biomarkers that are relevant to the prognosis of patients with NSCLC is urgently required.

Fascin-1 is a member of the $55 \mathrm{kDa}$ globular fascin family of proteins that contain four tandem fascin domains, each of which corresponds structurally to a $\beta$-trefoil fold (Machesky and $\mathrm{Li}, 2010$ ). Fascin-1 generally localizes to protrusions underneath the plasma membrane and plays an important role in the organization of several types of actin-based structures such as filopodia, spikes, lamellipodial ribs, dendrites, and microvilli (Kureishy et al., 2002; Hashimoto et al., 2011). The overexpression of fascin-1 can decrease cell-to-cell adhesion and increase epithelial cell motility (Kureishy et al., 2002; Hashimoto et al., 2011).

Laminin-5 is an extracellular matrix (ECM) protein with a cruciform structure composed of a long arm and three short arms. The laminin-5 molecule consists of $\alpha 3$, $\beta 3$, and $\gamma 2$ chains, the latter two being unique to this isoform (Niessen et al., 1994). Laminin-5 can promote cell migration and scattering (Kikkawa et al., 1994; Zhang and Kramer, 1996). Since laminin-5 contains Epidermal Growth Factor (EGF)-like repeats in the short arms, it may interact with one of its many potential ligands to mediate diverse cellular functions, including activation of EGFR signaling, similar to integrins (Engel, 1996). Being an extracellular matrix protein, laminin-5 plays an important role in cell migration (Fukai et al., 2005) and may be relevant for disease progression from adenocarcinoma in situ (AIS) to lepidic predominant adenocarcinoma (LPA) of the lung (Naito et al., 2016).

Previous studies have showed that both the expression of fascin-1 and laminin-5 were associated with the invasiveness and prognoses of several cancers, including colorectal (Adams, 2015; Fukazawa et al., 2015), gastric (Saito et al., 2010; Tu et al., 2016), pancreatic (Tsai et al., 2013; Chen et al., 2015) cancers and breast adenocarcinomas (D'Alfonso et al., 2015; Wang et al., 2016). Recently, some authors reported that the expression of fascin-1 and laminin-5 were associated with clinico-pathological characteristics of non-small cell lung cancer (Moriya et al., 2001; Niki et al., 2002; Pelosi et al., 2003; Choi et al., 2006; An et al., 2012; Ling et al., 2015; Luo et al., 2015; Zhao et al., 2015; Liu et al., 2016). However, reports regarding the clinical significance of both the expression and serum levels of fascin-1 and laminin-5 in non-small cell lung cancer are scarce.

In this study, we analyzed the expression and the serum levels of fascin- 1 and laminin-5 in patients with non-small cell lung cancer and evaluated their clinical significance.

\section{MATERIAL AND METHODS}

\section{Patients}

This study was approved by the review board of the Beijing Chest Hospital of Capital

Genetics and Molecular Research 16 (2): gmr16029617 
Medical University and all patients gave written informed consent. The specimens were anonymized and handled according to accepted ethical and legal standards.

The patients were divided into two groups; group 1 (Table 1) contained 224 patients with stage I and II NSCLC who were being surgically treated at the Beijing Chest Hospital of the Capital Medical University during January 2011-June 2013, whereas group 2 (Table 2) contained 154 patients with stage I and II NSCLC who were surgically treated at the same hospital from July 2013 to December 2014. The hematoxylin and eosin (H\&E)-stained slides of all the patients were reviewed in each case to confirm the original diagnosis that was based on the criteria accepted by the World Health Organization. The disease stage was determined based on the 7th tumor, node, and metastasis (TNM) classification of The International Association for the Study of Lung Cancer's (IASLC) staging manual. No preoperative chemotherapy or radiotherapy had been performed in any of these cases. Standard lobectomy and lymph node dissections were performed in every case. The postoperative treatments were performed according to the National Comprehensive Cancer Network's (NCCN) guideline. Cases with any other malignancies that occurred before or after the occurrence of the primary lung cancer were excluded from our study.

Table 1. Patients of group 1.
\begin{tabular}{l|c}
\hline Group 1 & No. of cases (N $=224)$ \\
\hline Male & 122 \\
\hline Female & 102 \\
\hline Stage I & 95 \\
\hline Stage II & 129 \\
\hline Relapsed & 76 \\
\hline No relapsed & 148 \\
\hline
\end{tabular}

Table 2. Patients of group 2.

\begin{tabular}{l|c}
\hline Group2 & No. of cases $(\mathrm{N}=154)$ \\
\hline Male & 89 \\
\hline Female & 65 \\
\hline Stage I & 53 \\
\hline Stage II & 101 \\
\hline Relapsed & 18 \\
\hline No relapsed & 136 \\
\hline
\end{tabular}

We determined the expression of fascin- 1 and laminin-5 in all patients and measured their levels in the serum of the group 2 patients before the surgery. All patients were followed up after the surgery. The serum levels of fascin-1 and laminin-5 in 150 normal individuals were measured to determine the threshold levels.

\section{Immunohistochemistry}

Formalin-fixed and paraffin-embedded tissue samples obtained during surgery were cut into 4-micrometer-thick sections and investigated. The primary antibodies used in the study were mouse monoclonal antibody directed against fascin-1 (Cloud-Clone Corp, Houston, Texas, USA) and laminin-5 (Cloud-Clone Corp, USA). Immunohistochemical staining methods were employed according to the manufacturer's instructions. Paraffin sections were washed with an ethanol series $(100,100,95,90,80,70 \%$ ethanol) and double 
distilled water according to standard protocols. Heat-induced antigen retrieval was performed in citrate buffer and boiled for $10 \mathrm{~min}$. After antigen retrieval, sections were treated with $3 \%$ hydrogen peroxide and $1 \%$ bovine serum albumin to block the endogenous peroxidase activity and non-specific binding. The sections were incubated with fascin- 1 and laminin-5 antibodies overnight at $48^{\circ} \mathrm{C}$. After washing with phosphate buffered saline, the tissue sections were incubated with the biotinylated secondary antibody and streptavidin-horseradish peroxidase complex, each for $30 \mathrm{~min}$ at room temperature. Diaminobenzidine was used as the chromogen, and tissue sections were counterstained with hematoxylin and viewed under a bright-field microscope.

The cells were divided into the following categories according to staining intensity: 0 points for no staining, 1 point for pale yellow staining, 2 points for yellowish-brown staining, and 3 points for brown staining. The percentage of positive-staining cells was counted as following: $<10 \%=0 ; 11-30 \%=1 ; 31-60 \%=2 ;>60 \%=3$. The final score was determined by the combined staining score and proportion score (intensity score $\mathrm{x}$ proportion score). For statistical analysis, final staining scores of $0,1-4$, and $>4$ were considered to be negative, moderate, and positive, respectively (Figures 1 and 2).

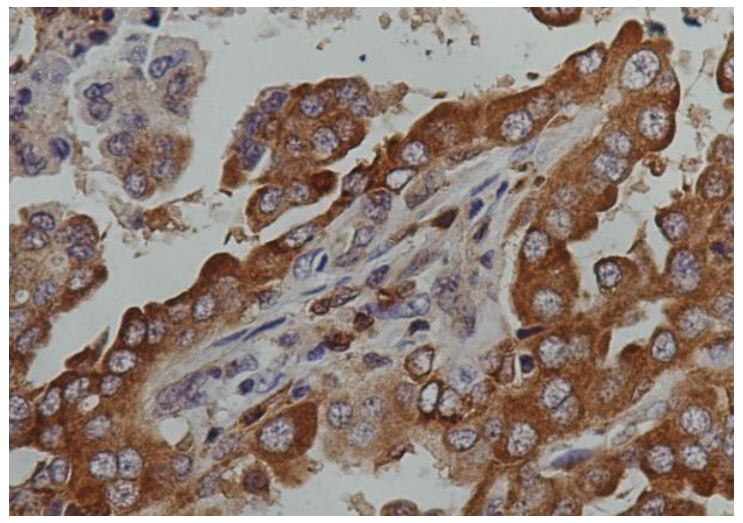

Figure 1. Positive expression of fascin-1 in NSCLC tissues.

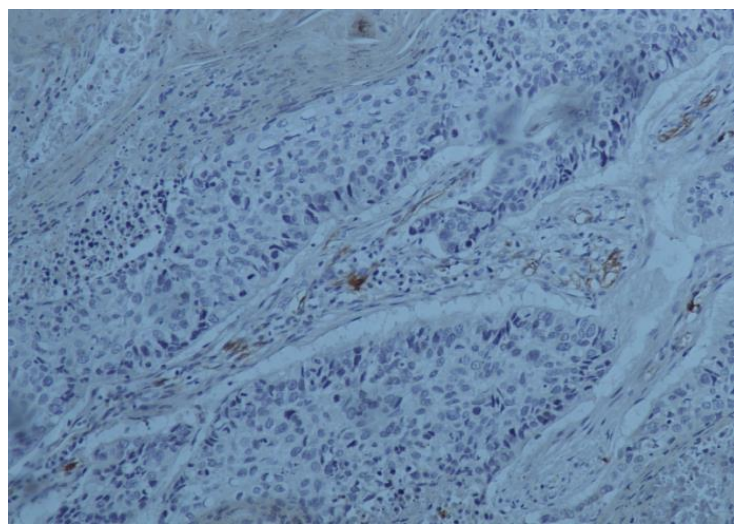

Figure 2. Negative expression of fascin-1 in NSCLC tissues. 


\section{Measurements of serum fascin-1 and laminin-5 levels}

Serum samples were obtained from the patients at the time of diagnosis; those who had received preoperative adjuvant therapy such as radiotherapy or chemotherapy at enrollment were excluded from the study. Normal volunteers recruited from among individuals undergoing annual physical examination showed no evidence of malignancy. In brief, clotted serum samples were separated by centrifugation at 3,000 rpm for $15 \mathrm{~min}$ at room temperature and stored in aliquots at $-80^{\circ} \mathrm{C}$ until use.

The fascin-1 and laminin-5 levels were measured using enzyme-linked immunosorbent assay (ELISA) commercial kits (Cloud-Clone Corp, Houston, Texas, USA) according to the manufacturer's instructions.

\section{Statistical analysis}

Statistical evaluations between different groups were performed using the chi-square test of the SPSS 16.0 software. P values less than 0.05 were considered to be statistically significant.

\section{RESULTS}

\section{The threshold values}

The threshold values were determined as the mean value plus two-folds of standard deviation. The threshold values of fascin- 1 and laminin- 5 were $4.351 \mathrm{ng} / \mathrm{mL}$ and $152 \mathrm{ng} / \mathrm{mL}$, respectively.

\section{Association between fascin-1 expression and relapse of NSCLC}

The expression of fascin- 1 and laminin-5 in the patients of the current series were divided into three grades: negative, moderate, and positive. There were 80 positive, 164 moderate, and 134 negative cases. Following were the percentages in the three grades for patients with relapse of the disease during the follow-up: 44 (55\%) negative, $36(21.9 \%)$ moderate, and $14(10.4 \%)$ positive $(\mathrm{P}=0.000)$ (Table 3$)$. This indicated that the expression of fascin-1 was related to the relapse of NSCLC in these patients.

Table 3. Association between the expression of fascin-1 and relapse of patients with NSCLC.

\begin{tabular}{l|c|c|c|c}
\hline Expression of fascin-1 & & Relapse & No relapse & \\
\hline Positive & 80 & 44 & 36 & $\chi=54.537$ \\
\hline Moderate & 164 & 36 & 128 & $\mathrm{P}=0.000$ \\
\hline Negative & 134 & 14 & 120 & \\
\hline
\end{tabular}

\section{Association between laminin-5 expression and the relapse of NSCLC}

The expression of laminin-5 in patients of the current series was divided into three grades: negative, moderate, and positive. There were 124 positive, 176 moderate, and 78 negative cases. The percentage of patients with relapse during the follow-up were 48 (38.7\%) negative, $38(21.6 \%)$ moderate, and $8(10.3 \%)$ positive, respectively $(\mathrm{P}=0.002)$ (Table 4$)$. 
This indicated that the expression of laminin-5 was related to the relapse of NSCLC in these patients.

Table 4. Association between the expression of fascin-1 and the relapse of NSCLC.

\begin{tabular}{l|c|c|c|c}
\hline Expression of laminin-5 & & Relapse & No relapse & \\
\hline Positive & 124 & 48 & 76 & $\chi=16.323$ \\
\hline Moderate & 176 & 38 & 138 & $\mathrm{P}=0.001$ \\
\hline Negative & 78 & 8 & 70 & \\
\hline
\end{tabular}

\section{The expression of fascin-1 and laminin-5 in patients with NSCLC}

The expression of both fascin-1 and laminin-5 were positive or moderate in 226 patients, among which 66 (29.2\%) patients showed symptoms of relapse during the follow-up. Among the 152 patients with negative expression of either fascin-1 or laminin-5, 28 (18.4\%) patients showed signs of relapse during the follow-up. The rates of relapse in the two groups were statistically different $(\mathrm{P}=0.017)$ (Table 5).

Table 5. Expression of fascin-1 and laminin-5 in patients with NSCLC.

\begin{tabular}{l|c|c|c}
\hline Expression of fascin-1 and laminin-5 & Relapse & No relapse & \\
\hline All positive or moderate & 66 & 160 & $\chi=5.655$ \\
\hline Atleast one negative & 28 & 124 & $\mathrm{P}=0.017$ \\
\hline
\end{tabular}

\section{Serum level and expression of fascin-1 in patients with NSCLC}

Among 154 patients, the serum fascin-1 levels of 48 patients were positive and 106 were negative. The number of patients with relapse in the positive and negative groups were $10(20.83 \%)$ and $8(7.55 \%)$, respectively, and the rates of relapse of the two groups were statistically different $(\mathrm{P}=0.015)$ (Table 6).

Table 6. Serum levels of fascin-1 in patients with NSCLC.
\begin{tabular}{l|c|c|c}
\hline Fascin-1 level & Relapse & No relapse & \\
\hline Positive & 10 & 38 & $\chi=5.868$ \\
\hline Negative & 8 & 98 & $P=0.015$ \\
\hline
\end{tabular}

There were 40 patients with positive serum levels of fascin- 1 and positive or moderate expression of fascin-1 (Table 7). Among them, 9 patients (22.5\%) relapsed during the followup, and the rate of relapse was higher than those of other patients $(\mathrm{P}=0.046)$.

Table 7. Serum level and expression of fascin-1 in patients with NSCLC.

\begin{tabular}{l|c|c|c}
\hline Serum level and expression of fascin-1 & Relapse & No relapse & \\
\hline Fascin-1 level and positive or moderate expression of Fascin-1 & 9 & 31 & $\chi=5.258$ \\
\hline At least one negative & 9 & 105 & $\mathrm{P}=0.046$ \\
\hline
\end{tabular}

\section{Serum level and expression of laminin-5 in patients with NSCLC}

Among 154 patients, the serum levels of laminin-5 of 39 patients were positive and 
115 were negative. The number of patients with relapse in the positive and negative groups were $9(23.07 \%)$ and $9(7.83 \%)$ respectively, and the rates of relapse of the two groups were statistically different $(\mathrm{P}=0.043)$ (Table 8$)$.

Table 8. Serum levels of laminin-5 in patients with NSCLC.

\begin{tabular}{l|c|c|c}
\hline Laminin-5 level & Relapse & No relapse & \\
\hline Positive & 9 & 30 & $\chi=4.114$ \\
\hline Negative & 9 & 106 & $\mathrm{P}=0.043$ \\
\hline
\end{tabular}

The serum levels of laminin-5 were positive and the expression of laminin-5 was positive or moderate in 30 patients (Table 9). Among them, 5 patients $(20 \%)$ relapsed during the follow-up, and the rates of relapse were not statistically different from those of other patients $(\mathrm{P}=0.046)$.

Table 9. Serum level and expression of laminin-5 in patients with NSCLC.

\begin{tabular}{l|c|c|c}
\hline Serum level and expression of laminin-5 & Relapse & No relapse & \\
\hline Laminin-5 level positive and positive or moderate expression of laminin-5 & 5 & 25 & $\chi=0.895$ \\
\hline At least one negative & 13 & 111 & $\mathrm{P}=0.344$ \\
\hline
\end{tabular}

\section{DISCUSSION}

Fascin actin-binding protein 1 (Fascin-1) is a 55-kDa conserved actin bundling protein, which is important for the maintenance and stability of parallel bundles of filamentous actin in different cell types (Adams, 2004; Hashimoto et al., 2011). The phosphorylation of protein kinase $C$ can adjust the binding activity of fascin and actin (De Arcangelis et al., 2004). Consequently, specific assembly and disintegration of the actin filament changes the mobility of cells by reducing intra and intercellular adhesion as well as adhesion between cells and the matrix (Yamashiro, 2012). Therefore, the overexpression of fascin-1 can decrease cell-to-cell adhesion and increase epithelial cell motility and may be associated with the invasiveness and metastatic ability of tumor cells (Kureishy et al., 2002; Hashimoto et al., 2011). In fact, studies in mouse tumor models showed that the fascin-1 levels were elevated and the invasive and metastatic abilities of tumor cells were strengthened (Ma et al., 2013). Laminin-5, composed of $\alpha 3, \beta 3$, and $\gamma 2$ chains, is an epithelial basement membrane-specific variant (Rousselle and Beck, 2013). The main role of laminin-5 in normal tissues is the maintenance of epithelialmesenchymal cohesion in tissues exposed to external forces, including the skin and stratified squamous mucosa (Rousselle et al., 1991; Rousselle et al., 1997). During tissue injury, laminin-5 induces migration of keratinocytes and promotes cell migration and wound closure (Verrando et al., 1994). Reports show that laminin-5 in culture promotes cell migration and scattering (Zhang and Kramer, 1996). In addition, laminin-5 is secreted by several squamous cell carcinoma lines, and is involved in tumor metastasis and invasion (Miyazaki, 2006).

Recent studies highlighted the association between the expression of fascin- 1 and laminin-5 and the prognoses of NSCLC. Pelosi et al. (2003) and Choi et al. (2006) indicated the value of fascin-1 immunoreactivity for predicting lymph node metastases. Several other groups showed that the fascin- 1 expression is significantly associated with the prognoses of NSCLC and may be a useful prognostic indicator (Ling et al., 2015; Luo et al., 2015; Zhao et al., 2015). Niki et al. (2002) showed laminin-5 expression at the invasive front of lung adenocarcinomas,

Genetics and Molecular Research 16 (2): gmr16029617 
and Moriya et al. (2001) and An et al. (2012) showed that overexpression of laminin-5 may be a useful prognostic factor in patients with NSCLC. Our result showed that the expression of fascin- 1 and laminin-5 were related to the relapse of NSCLC in patients, which corroborates previous findings. We evaluated the co-expression of fascin- 1 and laminin-5 and found that the rates of relapse of the two groups (patients showing positive/moderate expression of fascin-1 and laminin-5 or expressing only one of the two proteins) were statistically different $(\mathrm{P}=$ 0.017 ). To our knowledge, this is the first report that shows that fascin- 1 and laminin-5 coexpression can be used as a prognostic marker for relapse of NSCLC.

Recently, reports regarding serum levels of fascin-1 and laminin-5 in patients with NSCLC have been published. Teng and his colleagues indicated that the serum levels of fascin-1 and laminin-5 were associated with poor prognosis in NSCLC (Teng et al., 2013; Teng et al., 2016). We measured the serum levels of fascin-1 and laminin-5 in 154 patients with NSCLC prior to surgery. Among the 154 patients, the rate of relapse in patients with fascin-1 positivity and negativity were 20.83 and $7.55 \%$ respectively. Among these patients, the serum laminin-5 levels of 39 patients were positive and 115 were negative. The number of patients with relapse in the positive and negative groups were $9(23.07 \%)$ and $9(7.83 \%)$, respectively. The rates of relapse of the two groups were statistically significant.

Theoretically, simultaneous use of the serum levels and expressions of fascin- 1 and laminin-5 may improve the evaluation of NSCLC prognoses. Our results showed that 40 patients had positive serum levels of fascin-1 and positive/moderate expression of fascin-1. Among them, 9 patients (22.5\%) showed signs of relapse during the follow-up, and the rate of relapse was higher than those in other patients $(\mathrm{P}=0.046)$. However, similar correlation was not identified for laminin-5, the reason for which is not clear at present. We speculate that the small sample size could be one of the reasons. Further investigations are required to understand the involvement of laminin-5 in NSCLC prognosis.

\section{CONCLUSIONS}

Our results indicated that both serum levels and expression of fascin- 1 and laminin- 5 could be prognostic factors for patients with NSCLC. Simultaneous use of these factors may lead to more effective evaluation of the disease prognoses.

\section{Conflict of interests}

The authors declare no conflict of interest.

\section{ACKNOWLEDGMENTS}

Research supported by the Beijing Municipal Education Commission (\#KM201410025025). We would like to acknowledge and thank our colleagues of the medical record department for their support and help.

\section{REFERENCES}

Adams JC (2004). Roles of fascin in cell adhesion and motility. Curr. Opin. Cell Biol. 16: 590-596. https://doi.org/10.1016/j. ceb.2004.07.009

Genetics and Molecular Research 16 (2): gmr16029617 
Adams JC (2015). Fascin-1 as a biomarker and prospective therapeutic target in colorectal cancer. Expert Rev. Mol. Diagn. 15: 41-48. https://doi.org/10.1586/14737159.2015.976557

An SJ, Lin QX, Chen ZH, Su J, et al. (2012). Combinations of laminin 5 with PTEN, p-EGFR and p-Akt define a group of distinct molecular subsets indicative of poor prognosis in patients with non-small cell lung cancer. Exp. Ther. Med. 4: 226-230.

Chen J, Wang W, Wei J, Zhou D, et al. (2015). Overexpression of $\beta 3$ chains of laminin-332 is associated with clinicopathologic features and decreased survival in patients with pancreatic adenocarcinoma. Appl. Immunohistochem. Mol. Morphol. 23: 516-521. https://doi.org/10.1097/PAI.0000000000000115

Choi PJ, Yang DK, Son CH, Lee KE, et al. (2006). Fascin immunoreactivity for preoperatively predicting lymph node metastases in peripheral adenocarcinoma of the lung $3 \mathrm{~cm}$ or less in diameter. Eur. J. Cardiothorac. Surg. 30: 538542. https://doi.org/10.1016/j.ejcts.2006.06.029

D'Alfonso TM, Ross DS, Liu YF and Shin SJ (2015). Expression of p40 and laminin 332 in metaplastic spindle cell carcinoma of the breast compared with other malignant spindle cell tumours. J. Clin. Pathol. 68: 516-521. https:// doi.org/10.1136/jclinpath-2015-202923

De Arcangelis A, Georges-Labouesse E and Adams JC (2004). Expression of fascin-1, the gene encoding the actinbundling protein fascin-1, during mouse embryogenesis. Gene Expr. Patterns 4: 637-643. https://doi.org/10.1016/j. modgep.2004.04.012

Engel J (1996). Domain organizations of modular extracellular matrix proteins and their evolution. Matrix Biol. 15: 295 299. https://doi.org/10.1016/S0945-053X(96)90130-4

Ferlay J, Soerjomataram I, Ervik M, Dikshit R, et al. (2013). GLOBOCAN 2012 v1.0, cancer incidence and mortality worldwide: IARC cancer base No. 11 [Internet]. International Agency for Research on Cancer. http://globocan.iarc.fr.

Fitzmaurice C, Dicker D, Pain A, Hamavid H, et al.; Global Burden of Disease Cancer Collaboration (2015). The global burden of cancer 2013. JAMA Oncol. 1: 505-527. https://doi.org/10.1001/jamaoncol.2015.0735

Fukai Y, Masuda N, Kato H, Fukuchi M, et al. (2005). Correlation between laminin-5 gamma2 chain and epidermal growth factor receptor expression in esophageal squamous cell carcinomas. Oncology 69: 71-80. https://doi. org $/ 10.1159 / 000087477$

Fukazawa S, Shinto E, Tsuda H, Ueno H, et al. (2015). Laminin $\beta 3$ expression as a prognostic factor and a predictive marker of chemoresistance in colorectal cancer. Jpn. J. Clin. Oncol. 45: 533-540.

Hashimoto Y, Kim DJ and Adams JC (2011). The roles of fascins in health and disease. J. Pathol. 224: 289-300. https:// doi.org/10.1002/path.2894

Kikkawa Y, Umeda M and Miyazaki K (1994). Marked stimulation of cell adhesion and motility by ladsin, a laminin-like scatter factor. J. Biochem. 116: 862-869. https://doi.org/10.1093/oxfordjournals.jbchem.a124608

Kureishy N, Sapountzi V, Prag S, Anilkumar N, et al. (2002). Fascins, and their roles in cell structure and function. BioEssays 24: 350-361. https://doi.org/10.1002/bies.10070

Ling XL, Zhang T, Hou XM and Zhao D (2015). Clinicopathological significance of fascin-1 expression in patients with non-small cell lung cancer. Onco Targets Ther. 8: 1589-1595.

Liu CC, Lin JH, Hsu TW, Hsu JW, et al. (2016). Collagen XVII/laminin-5 activates epithelial-to-mesenchymal transition and is associated with poor prognosis in lung cancer. Oncotarget. Aug. 11: 11208-11213.

Luo A, Yin Y, Li X, Xu H, et al. (2015). The clinical significance of FSCN1 in non-small cell lung cancer. Biomed. Pharmacother. 73: 75-79. https://doi.org/10.1016/j.biopha.2015.05.014

Ma Y, Li A, Faller WJ, Libertini S, et al. (2013). Fascin 1 is transiently expressed in mouse melanoblasts during development and promotes migration and proliferation. Development 140: 2203-2211. https://doi.org/10.1242/dev.089789

Machesky LM and Li A (2010). Fascin: Invasive filopodia promoting metastasis. Commun. Integr. Biol. 3: 263-270. https://doi.org/10.4161/cib.3.3.11556

Miyazaki K (2006). Laminin-5 (laminin-332): Unique biological activity and role in tumor growth and invasion. Cancer Sci. 97: 91-98 . https://doi.org/10.1111/j.1349-7006.2006.00150.x

Moriya Y, Niki T, Yamada T, Matsuno Y, et al. (2001). Increased expression of laminin-5 and its prognostic significance in lung adenocarcinomas of small size. An immunohistochemical analysis of 102 cases. Cancer 91: 1129-1141. https:// doi.org/10.1002/1097-0142(20010315)91:6<1129::AID-CNCR1109>3.0.CO;2-C

Naito M, Aokage K, Saruwatari K, Hisakane K, et al. (2016). Microenvironmental changes in the progression from adenocarcinoma in situ to minimally invasive adenocarcinoma and invasive lepidic predominant adenocarcinoma of the lung. Lung Cancer 100: 53-62. https://doi.org/10.1016/j.lungcan.2016.07.024

Niessen CM, Hogervorst F, Jaspars LH, de Melker AA, et al. (1994). The alpha 6 beta 4 integrin is a receptor for both laminin and kalinin. Exp. Cell Res. 211: 360-367. https://doi.org/10.1006/excr.1994.1099

Niki T, Kohno T, Iba S, Moriya Y, et al. (2002). Frequent co-localization of Cox-2 and laminin-5 gamma2 chain at the

Genetics and Molecular Research 16 (2): gmr16029617 
invasive front of early-stage lung adenocarcinomas. Am. J. Pathol. 160: 1129-1141. https://doi.org/10.1016/S00029440(10)64933-4

Page GP, Green JL and Lackland D (2000). Epidemiology of lung cancer with special reference to genetics, bioassays, women, and developing countries. Semin. Respir. Crit. Care Med. 21: 365-373. https://doi.org/10.1055/s-2000-9403

Pelosi G, Pasini F, Fraggetta F, Pastorino U, et al. (2003). Independent value of fascin immunoreactivity for predicting lymph node metastases in typical and atypical pulmonary carcinoids. Lung Cancer 42: 203-213. https://doi. org/10.1016/S0169-5002(03)00294-0

Rousselle P and Beck K (2013). Laminin 332 processing impacts cellular behavior. Cell Adhes. Migr. 7: 122-134. https:// doi.org/10.4161/cam.23132

Rousselle P, Lunstrum GP, Keene DR and Burgeson RE (1991). Kalinin: an epithelium-specific basement membrane adhesion molecule that is a component of anchoring filaments. J. Cell Biol. 114: 567-576. https://doi.org/10.1083/ jeb.114.3.567

Rousselle P, Keene DR, Ruggiero F, Champliaud MF, et al. (1997). Laminin 5 binds the NC-1 domain of type VII collagen. J. Cell Biol. 138: 719-728. https://doi.org/10.1083/jcb.138.3.719

Saito Y, Sekine W, Sano R, Komatsu S, et al. (2010). Potentiation of cell invasion and matrix metalloproteinase production by alpha3beta1 integrin-mediated adhesion of gastric carcinoma cells to laminin-5. Clin. Exp. Metastasis 27: 197205. https://doi.org/10.1007/s10585-010-9314-3

Siegel R, Ma J, Zou Z and Jemal A (2014). Cancer statistics, 2014. CA Cancer J. Clin. 64: 9-29. https://doi.org/10.3322/ caac. 21208

Teng Y, Wang Z, Ma L, Zhang L, et al. (2016). Prognostic significance of circulating laminin gamma2 for early-stage nonsmall-cell lung cancer. Onco Targets Ther. 9: 4151-4162. https://doi.org/10.2147/OTT.S105732

Teng Y, Xu S, Yue W, Ma L, et al. (2013). Serological investigation of the clinical significance of fascin in non-small-cell lung cancer. Lung Cancer 82: 346-352. https://doi.org/10.1016/j.lungcan.2013.08.017

Torre LA, Siegel RL and Jemal A (2016). Lung cancer statistics. Adv. Exp. Med. Biol. 893: 1-19. https://doi.org/10.1007/9783-319-24223-1 1

Tsai WC, Lin CK, Lee HS, Gao HW, et al. (2013). The correlation of cortactin and fascin-1 expression with clinicopathological parameters in pancreatic and ampulla of Vater adenocarcinoma. APMIS 121: 171-181. https:// doi.org/10.1111/j.1600-0463.2012.02952.x

Tu L, Xu J, Wang M, Zhao WY, et al. (2016). Correlations of fascin-1 and cadherin-17 protein expression with clinicopathologic features and prognosis of patients with gastric cancer. Tumour Biol. 37: 8775-8782. https://doi. org/10.1007/s13277-015-4368-0

Verrando P, Lissitzky JC, Sarret Y, Winberg JO, et al. (1994). Keratinocytes from junctional epidermolysis bullosa do adhere and migrate on the basement membrane protein nicein through alpha 3 beta 1 integrin. Lab. Invest. 71: 567-574.

Wang CQ, Tang CH, Chang HT, Li XN, et al. (2016). Fascin-1 as a novel diagnostic marker of triple-negative breast cancer. Cancer Med. 5: 1983-1988. https://doi.org/10.1002/cam4.746

Wu CF, Fu JY, Yeh CJ, Liu YH, et al. (2015). Recurrence risk factors analysis for stage I non-small cell lung cancer. Medicine (Baltimore) 94: e1337. https://doi.org/10.1097/MD.0000000000001337

Yamashiro S (2012). Functions of fascin in dendritic cells. Crit. Rev. Immunol. 32: 11-21. https://doi.org/10.1615/ CritRevImmunol.v32.i1.20

Zhang K and Kramer RH (1996). Laminin 5 deposition promotes keratinocyte motility. Exp. Cell Res. 227: 309-322. https://doi.org/10.1006/excr.1996.0280

Zhao W, Gao J, Wu J, Liu QH, et al. (2015). Expression of Fascin-1 on human lung cancer and paracarcinoma tissue and its relation to clinicopathological characteristics in patients with lung cancer. Onco Targets Ther. 8: 2571-2576.

Genetics and Molecular Research 16 (2): gmr16029617 